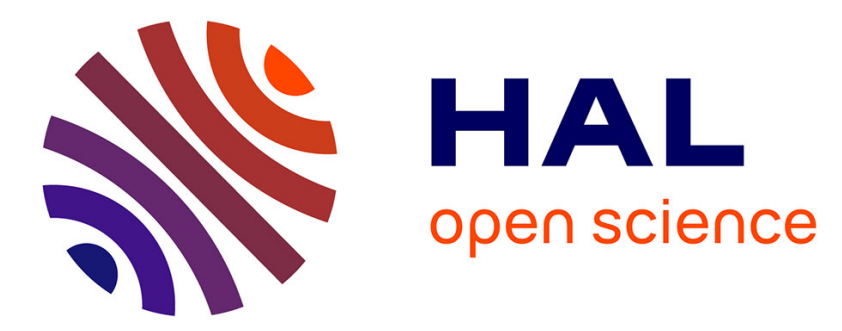

\title{
Yb-doped zinc tin oxide thin film and its application to $\mathrm{Cu}(\mathrm{InGa}) \mathrm{Se} 2$ solar cells
}

Youngsang Park, Gerald Ferblantier, Abdelilah Slaoui, Aziz Dinia, Hyeonwook Park, Salh Alhammadi, Woo Kyoung Kim

\section{- To cite this version:}

Youngsang Park, Gerald Ferblantier, Abdelilah Slaoui, Aziz Dinia, Hyeonwook Park, et al.. Ybdoped zinc tin oxide thin film and its application to $\mathrm{Cu}(\mathrm{InGa}) \mathrm{Se} 2$ solar cells. Journal of Alloys and Compounds, 2020, 815, pp.152360. 10.1016/j.jallcom.2019.152360 . hal-02550925

\section{HAL Id: hal-02550925 \\ https://cnrs.hal.science/hal-02550925}

Submitted on 11 Dec 2020

HAL is a multi-disciplinary open access archive for the deposit and dissemination of scientific research documents, whether they are published or not. The documents may come from teaching and research institutions in France or abroad, or from public or private research centers.
L'archive ouverte pluridisciplinaire HAL, est destinée au dépôt et à la diffusion de documents scientifiques de niveau recherche, publiés ou non, émanant des établissements d'enseignement et de recherche français ou étrangers, des laboratoires publics ou privés. 


\title{
Yb-doped zinc tin oxide thin film and its application to $\mathrm{Cu}(\mathrm{InGa}) \mathrm{Se}_{2}$ solar cells
}

\author{
Youngsang Park ${ }^{\mathrm{a}}$, Gérald Ferblantier $^{\mathrm{b}}$, Abdelilah Slaoui ${ }^{\mathrm{b}}$, Aziz Dinia ${ }^{\mathrm{c}}$, Hyeonwook Park $^{\mathrm{a}}$, Salh Alhammadi ${ }^{\mathrm{a}}$, \\ Woo Kyoung $\mathrm{Kim}^{\text {a, * }}$ \\ a School of Chemical Engineering, Yeungnam University, Gyeongsan, Gyeongbuk, 38541, Republic of Korea \\ ${ }^{\mathrm{b}}$ ICube, CNRS-Université de Strasbourg, UMR 7357, 23 rue du Loess, BP 20 CR, 67037, Strasbourg Cedex 2, France \\ ' IPCMS, CNRS-Université de Strasbourg UMR 7504, 23 rue du Loess, BP 43, 67034, Strasbourg Cedex 2, France
}

\section{A R T I C L E IN F O}

\section{Article history:}

Received 1 May 2019

Received in revised form 17 September 2019

Accepted 19 September 2019

Available online $\mathrm{xxx}$

Keywords:

Ytterbium

Zinc tin oxide

$\mathrm{Cu}(\mathrm{InGa}) \mathrm{Se}_{2}$

Solar cell

Down-converter

\begin{abstract}
A B S T R A C T
The use of rare earth elements with semiconductor materials has attracted immense interest due to their unique properties. In this study, we investigated the characteristics of an ytterbium (Yb)-doped zinc tin oxide (Yb:ZTO) thin film and its application as a potential down-converter of $\mathrm{Cu}$ (InGa)Se ${ }_{2}$ (CIGS) thin-film solar cells. Yb:ZTO thin films were deposited by reactive sputtering of $\mathrm{Zn}$ and $\mathrm{Sn}$ metal with oxygen flow. A few pieces of $\mathrm{Yb}$ were embedded in a $\mathrm{Zn}$ metal target; thus $\mathrm{Yb}$ elements were supplied during $\mathrm{Zn}$ sputtering. The relative composition of $\mathrm{Zn}$ and $\mathrm{Sn}$ was controlled by changing the sputtering power (10-70 W) of Sn, in relation to the fixed sputtering power for $\mathrm{Zn}(70 \mathrm{~W})$. In addition, the substrate temperature was varied from room temperature to $400^{\circ} \mathrm{C}$. It was confirmed that a smaller amount of $\mathrm{Sn}$ with lower sputtering power led to more incorporation of $\mathrm{Yb}$ into ZTO. X-ray photoelectron spectroscopy analysis confirmed the incorporation of $\mathrm{Yb}$ into ZTO, and photoluminescence measurement demonstrated $\mathrm{Yb}$ emission. Grazing incidence $\mathrm{X}$-ray diffraction indicated the shift of ZTO emission peaks induced by the difference in the composition of $\mathrm{Zn}$ and Sn. Finally, CIGS solar cells with an Yb:ZTO layer were fabricated. The results suggested that cells with the highest $\mathrm{Yb}$ photoluminescence emission showed the highest short-circuit current density and cell efficiency.
\end{abstract}

(C) 2019

\section{Introduction}

Chalcopyrite $\mathrm{Cu}(\mathrm{InGa}) \mathrm{Se}_{2}$ (CIGS)-based thin film photovoltaic cells have continuously broken the record of cell conversion efficiency over the last few decades, which is currently at $23.35 \%$ (Solar Frontier 2019) [1] - superior to polycrystalline $\mathrm{Si}(22.3 \%$ [2]) and thin film CdTe $(21.0 \%$ [2]). The typical stack structure of CIGS cells follows the pattern substrate/Mo/CIGS/CdS/i-ZnO/ZnO:Al/grid, and various novel approaches on the individual stacked layers and interfaces have been explored to achieve a further increase in the cell performance [3-7]. Photon conversion effects including up-conversion, down-conversion, and down-shifting using modified transparent conductive layers have been studied as promising approaches to enhance the current collection of photovoltaic cells [8-10]. The photon up-conversion converts two or more low energy (e.g., typically lower than the band gap energy of light absorber) photons to a single high energy photon with energy higher than the band gap energy of absorber. Down-conversion is the process to convert a high energy photon to multiple lower energy photons of which energy is still higher than the band gap energy. Both up- and down-conversion processes reduce the loss of light absorption and thus enhance the short circuit current density of solar cells [11].

\footnotetext{
* Corresponding author.

Email address: wkim@ynu.ac.kr (W.K. Kim)
}

Several rare earth elements have been explored as potential candidates for a photon converter, including $\mathrm{Nd}[12,13]$, Tm [13], Eu [14], Pr [15], Er [16], Yb [16,17], and Dy [18] for a $\mathrm{ZnO}$ matrix. Rare earth element-doped $\mathrm{SnO}_{2}$ has been studied as well $[9,10,19,20]$. However, the study on the $\mathrm{Zn}-\mathrm{Sn}-\mathrm{O}$ (ZTO) matrix was hardly reported. ZTO material is inexpensive and chemically stable. Furthermore, it can be deposited by abundant and non-toxic sources and thus considered a promising candidate as a substitute for indium-doped tin oxide and intrinsic $\mathrm{ZnO}$ transparent conductors. In addition, it possesses both the optical transparency of $\mathrm{ZnO}$ and the excellent electrical conductivity of $\mathrm{SnO}_{2}$ [21]. It is known that the structural and optical properties of ZTO can be controlled by adjusting the composition of $\mathrm{Zn}$ and $\mathrm{Sn}$ in ZTO [22]. Recently, Dimitrievska et al. tried to dope $\mathrm{Eu}^{3+}$ ions into nanocrystalline $\mathrm{Zn}_{2} \mathrm{SnO}_{4}$ powders using a mechano-chemical solid-state reaction method [23]. In this paper, the ytterbium (Yb)-doped ZTO (Yb:ZTO) thin film was investigated. In particular, the effects of the relative composition of $\mathrm{Zn} / \mathrm{Sn}$ and substrate temperature during the co-sputtering process on $\mathrm{Yb}: \mathrm{ZTO}$ were measured and optimized processing parameters determined. In addition, the optimized $\mathrm{Yb}$ :ZTO layer was applied to $\mathrm{Cu}(\mathrm{InGa}) \mathrm{Se}_{2}$ (CIGS) thin-film solar cells. To the best of our knowledge, this is the first work to incorporate $\mathrm{Yb}$ into ZTO host, and investigate their compositional effects on optical properties, and apply the Yb:ZTO to solar cells. 


\section{Materials and methods}

Yb:ZTO thin films with a thickness of approximately $100 \mathrm{~nm}$ were prepared on $500 \mu \mathrm{m}$-thick p-type Si wafers with (100) orientation and a $1 \mathrm{~mm}$-thick glass substrate by the radio-frequency (RF) reactive-magnetron sputtering method with flowing $\mathrm{Ar}$ and $\mathrm{O}_{2}$ at $8 \mathrm{sccm}$ and $3 \mathrm{sccm}$, respectively. The $\mathrm{Yb}$-doped $\mathrm{Zn}(\mathrm{Yb}: \mathrm{Zn})$ and pure $\mathrm{Sn}$ targets were simultaneously sputtered at the sputtering power of $70 \mathrm{~W}$ (fixed) and 10-70 W(varied), respectively. The $\mathrm{Zn}$ (or Yb:Zn) and Sn targets have a 2 inch-diameter disk shape. The $\mathrm{Yb}: \mathrm{Zn}$ alloy target was prepared by implanting several pieces of small $\mathrm{Yb}$ pure metal $(99.99 \%, 70 \mathrm{~g}$ each) onto a pure $\mathrm{Zn}$ target. The substrate temperature varied from 100 to $400^{\circ} \mathrm{C}$ during initial experiments (to be optimized afterward.) The information on Sn sputtering power $(10-70 \mathrm{~W})$ and substrate temperature $\left(100-400^{\circ} \mathrm{C}\right)$ can be found in the sample ID. For example, sample $\mathrm{S} 10 \mathrm{~T} 3$ represents $10 \mathrm{~W}$ power and $300^{\circ} \mathrm{C}$ substrate temperature. During the sputtering process, the working pressure was maintained at $3.4 \mathrm{mTorr}(\sim 0.4533 \mathrm{~Pa})$ and the substrate was located approximately $12 \mathrm{~cm}$ above the target. For lateral homogeneity of film thickness, the substrate was rotated. The deposition rate was varied from approximately $3 \mathrm{~nm} / \mathrm{min}$ (for S10T3) to $20 \mathrm{~nm} / \mathrm{min}$ (for S70T3) depending on the sputtering power of Sn target, which was estimated by measuring the thickness of film after each deposition. Two halogen lamps were located behind the sample holder for heating the substrate.

The Yb:ZTO thin film has been employed as a transparent conducting oxide to replace an i-ZnO layer in a conventional CIGS solar cell structure of glass/Mo/CIGS/CdS/i-ZnO/Al:ZnO/grid, as shown in Fig. 1. A p-type CIGS light absorbing layer with a thickness of $1.5-1.7 \mu \mathrm{m}$ was fabricated by the reaction of $\mathrm{CuGa} / \mathrm{In}$ bilayer metal precursors with $\mathrm{H}_{2} \mathrm{Se}$ and $\mathrm{H}_{2} \mathrm{~S}$ gas. Bilayer $\mathrm{CuGa} / \mathrm{In}$ precursors were deposited on Mo-coated glass by the sequential DC sputtering of a $\mathrm{CuGa}$ alloy $(\sim 24 \mathrm{wt} \% \mathrm{Ga})$ and pure In targets, yielding a total $\mathrm{CuGa} / \mathrm{In}$ thickness of $500-600 \mathrm{~nm}$ and atomic composition of $\mathrm{Cu} /($ $\mathrm{Ga}+\mathrm{In})=0.85-0.95$ and $\mathrm{Ga} /(\mathrm{Ga}+\mathrm{In})=0.2-0.3$. The selenization of $\mathrm{CuGa} / \mathrm{In}$ precursors by $\mathrm{H}_{2} \mathrm{Se}$ gas was performed at $480-500^{\circ} \mathrm{C}$ for $25-35 \mathrm{~min}$, and then followed by the sulfurization by $\mathrm{H}_{2} \mathrm{~S}$ gas at $550-580^{\circ} \mathrm{C}$ for $60-90 \mathrm{~min}$.

The n-type buffer layer of CdS $(\sim 70 \mathrm{~nm})$ was deposited by chemical bath deposition. Yb:ZTO with a thickness of $100 \mathrm{~nm}$ was then deposited on CdS as a photon converter layer, followed by the DC sputter-deposition of n-type $\mathrm{Al}: \mathrm{ZnO}$ (AZO) with a thickness of about

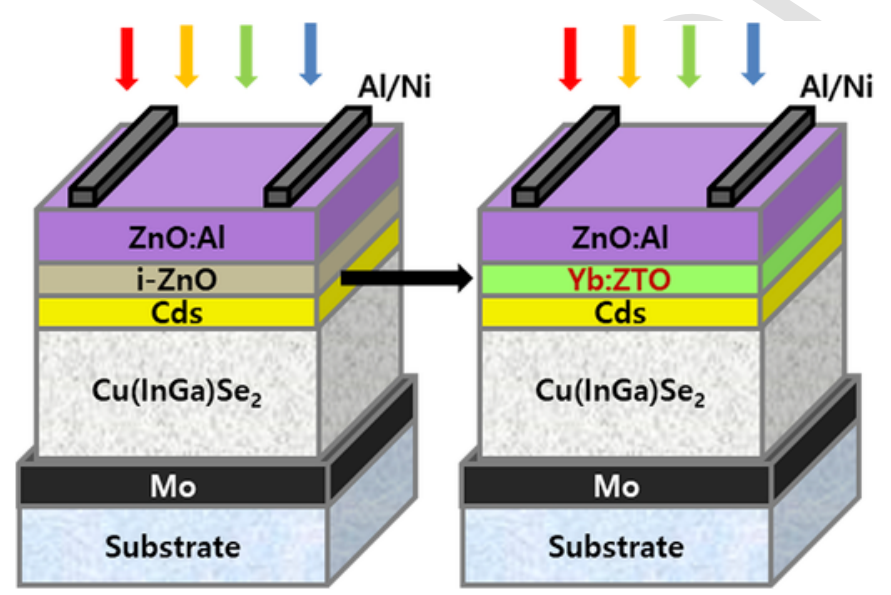

Fig. 1. Schematic diagram of CIGS solar cell structure: (left) conventional structure and (right) new structure with Yb:ZTO fabricated in this study.
$400 \mathrm{~nm}$. Finally, a Ni/Ag front grid was deposited by electron beam evaporation at room temperature.

The crystallography of the as-deposited Yb:ZTO thin films was analyzed by grazing incidence X-ray diffraction (GI-XRD; PANalytical X'Pert PRO MPD) with $\mathrm{CuK} \alpha_{1}$ radiation $(\lambda=0.154056 \mathrm{~nm})$ at an incidence angle of $\omega=0.4^{\circ}$. The thickness of the thin films was measured using a spectroscopic ellipsometer (HORIBA Uvisel ${ }^{\mathrm{TM}} \mathrm{Lt}$ M200 FGMS) in the range of $210-880 \mathrm{~nm}$. The doping concentration of $\mathrm{Yb}$ in the ZTO thin films was estimated by X-ray photoelectron spectroscopy (XPS, K-Alpha) surface scans at operating conditions of $400 \mu \mathrm{m}$ spot size, $200 \mathrm{eV}$ pass energy, $0.1 \mathrm{eV}$ step size, and the constant analyzer energy (CAE) mode. A photoluminescence (PL) measurement was carried out in the $300-1050 \mathrm{~nm}$ range of wavelength using a frequency-tripled neodymium-doped yttrium aluminum garnet (Nd-YAG) laser with a wavelength of $355 \mathrm{~nm}$. PL signals enter into an optical fiber and then are analyzed by a multi-channel CCD. The transmittance of the thin film was measured by a spectrophotometer (U-Perkin-Elmer Lambda 950) in the wavelength range of $300-1300 \mathrm{~nm}$. The current-voltage (I-V) characteristics of the CIGS solar cells were identified using a solar simulator (K3000 XE55 Solar Cell I-V Measurement System) with AM1.5 irradiation.

\section{Results and discussion}

\subsection{Effect of ZTO composition}

Fig. 2 presents the GI-XRD $\left(\omega=0.4^{\circ}\right)$ patterns of $\mathrm{Yb}: \mathrm{ZTO}$ thin films deposited at different $\mathrm{Sn}$ sputtering powers of 10-70 W, with a fixed $\mathrm{Yb}: \mathrm{Zn}$ alloy sputtering power of $70 \mathrm{~W}$ and substrate temperature of $300^{\circ} \mathrm{C}$. The XRD patterns of all samples except S10T3 look quite broad due to the probable formation of $\mathrm{ZnO}-\mathrm{SnO}_{2}$ or $\mathrm{Zn}-\mathrm{Sn}-\mathrm{O}$ alloys, which have been reported to be amorphous below approximately $450^{\circ} \mathrm{C}[22,24]$. However, S10T3 samples prepared using the lowest sputtering power $(10 \mathrm{~W})$ of the $\mathrm{Sn}$ target show sharp hexagonal $\mathrm{ZnO}$ (002) and (103) peaks by XRD analysis $[25,26]$, as summarized in Table 1; they also have only 1.31 at.\% Sn with $\mathrm{Sn} /(\mathrm{Zn}+\mathrm{Sn}) \sim 0.02$. Apparently, the increased Sn sputtering power resulted in the decreased intensity of the ZTO peak and its slight shift to a lower $2 \theta$ position, demonstrating the formation of more amorphous and higher Sn-containing ZTO. The low crystallinity of ZTO is partly attributable to the formation of stress by the different sizes of $\mathrm{Zn}$ and $\mathrm{Sn}$ ions [22]. In addition, increased $\mathrm{Sn}$ concentration may lead to the formation of SnO (JCPDS: 06-0395), $\mathrm{SnO}_{2}$ (JCPDS: 41-1445), and other oxygen-rich ZTO compounds such as spinel $\mathrm{Zn}_{2} \mathrm{SnO}_{4}$ (JCPDS: 24-1470) and ilmenite $\mathrm{ZnSnO}_{3}$ (JCPDS: 52-1381) [24]. However, the Yb doping concentration decreased with increased Sn sputtering power.

The chemical composition of ZTO alloys has been estimated by XPS analysis. Fig. 3 presents peaks near $185 \mathrm{eV}$ corresponding to the $\mathrm{Yb} 4 \mathrm{~d}_{5 / 2}$ core level of atoms bound to oxygen, confirming the formation of $\mathrm{Yb}-\mathrm{Zn}-\mathrm{Sn}-\mathrm{O}$ structure rather than the elemental $\mathrm{Yb}$ of which bind energy is near $182-183 \mathrm{eV}$ [27]. Even though the $\mathrm{Yb}$ ion can exist in a $2+$ oxidation state, it is hardly detected by XPS due to the very small difference in binding energy [28]. As shown in Fig. 3 and Table 1, the doping concentration of $\mathrm{Yb}$ in ZTO monotonically decreases with the sputtering power of the Sn target. In general, during doping, the crystalline structure of the host material is preferred to the amorphous structure because there are more available doping sites in crystalline materials than amorphous ones. For example, the wurtzite $\mathrm{ZnO}$ structure has empty tetrahedral and octahedral sites, which can be occupied by dopants, i.e., interstitial 


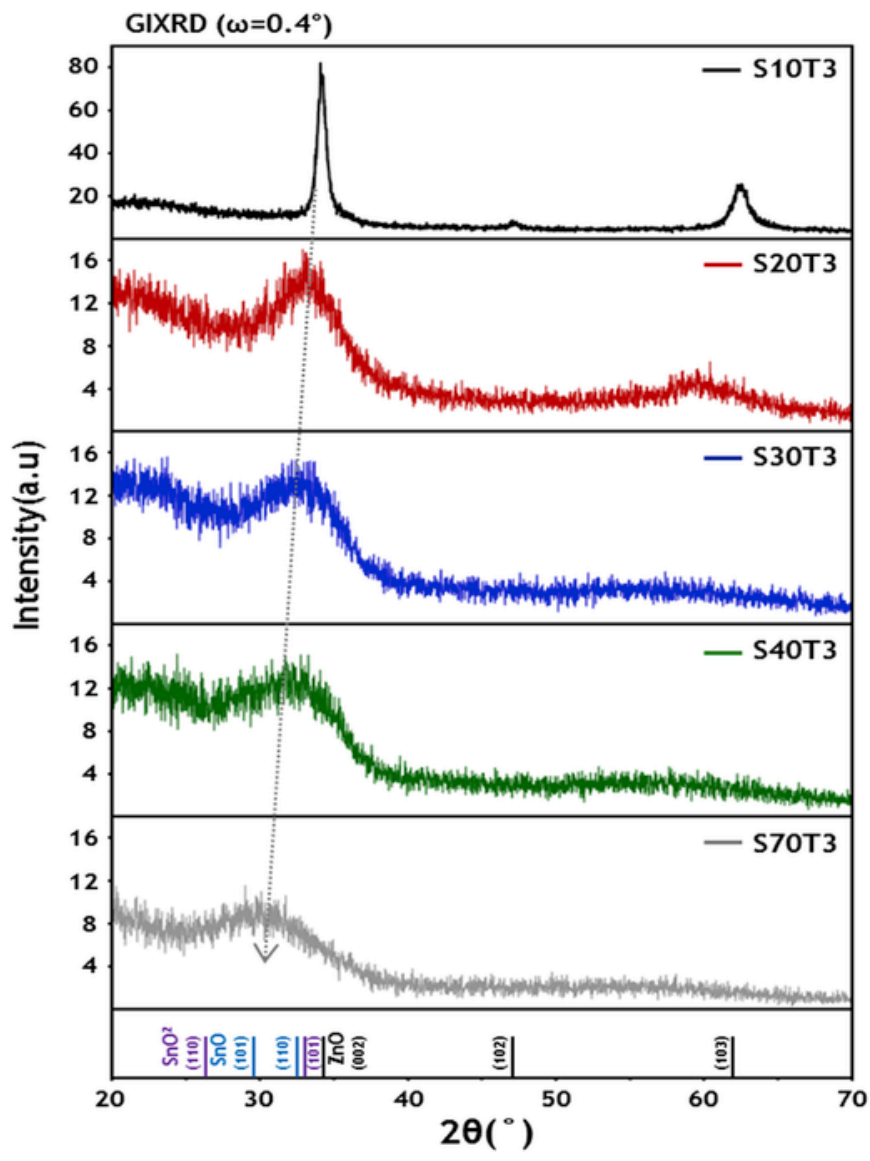

Fig. 2. GI-XRD patterns of the Yb:ZTO thin films deposited by different Sn sputtering powers in the range of $10-70 \mathrm{~W}$.

Table 1

Composition estimated by XPS spectra of Yb:ZTO films deposited at different Sn sputtering power.

\begin{tabular}{lllllll}
\hline Sample & $\begin{array}{l}\text { Zn 2p } \\
\text { (at.\%) }\end{array}$ & $\begin{array}{l}\text { Sn 3d } \\
\text { (at.\%) }\end{array}$ & Sn/(Zn + Sn) & $\begin{array}{l}\text { O 1s } \\
\text { (at.\%) }\end{array}$ & $\begin{array}{l}\text { Yb 4d } \\
\text { (at.\%) }\end{array}$ & $\begin{array}{l}\text { Band } \\
\text { gap } \\
\text { (eV) }\end{array}$ \\
\hline S10T3 & 52.2 & 1.31 & 0.02 & 46.2 & 0.25 & 3.28 \\
S20T3 & 40.8 & 12.8 & 0.24 & 46.2 & 0.18 & 3.33 \\
S30T3 & 31.2 & 17.0 & 0.35 & 51.6 & 0.17 & 3.80 \\
S40T3 & 21.6 & 21.0 & 0.49 & 57.2 & 0.12 & 3.70 \\
S70T3 & 4.57 & 22.2 & 0.83 & 73.1 & 0.09 & 3.10 \\
\hline
\end{tabular}

doping [29]. In addition, the grain boundary of a polycrystalline structure can be used as a penetration path for dopants [28]. However, the reduced crystallinity of the ZTO matrix by adding Sn, and thus increasing structural disorder, may restrict the incorporation of $\mathrm{Yb}$. The oxygen content approximately increases with increased Sn incorporation due to a higher oxidation state of $\mathrm{Sn}$ than $\mathrm{Zn}$, i.e., $\mathrm{SnO}_{2}$ vs. $\mathrm{ZnO}$. Considering the stoichiometry of each film, S10T3 is close to $\mathrm{ZnO}$; with increasing sputtering $\mathrm{Sn}$ power the film composition changes successively to $\mathrm{Zn}_{3} \mathrm{SnO}_{4}, \mathrm{Zn}_{2} \mathrm{SnO}_{3}, \mathrm{ZnSnO}_{3}$, and $\mathrm{SnO}_{2}$ from the S20T3 to the S70T3 samples, respectively. From XPS results, it was confirmed that $\mathrm{Yb}$ was incorporated from the crystalline structure to amorphous structure.

The optical activation of the Yb:ZTO thin films was investigated using PL spectroscopy. The PL spectra of Yb:ZTO thin films prepared by different Sn sputtering power were obtained using a $355 \mathrm{~nm}$

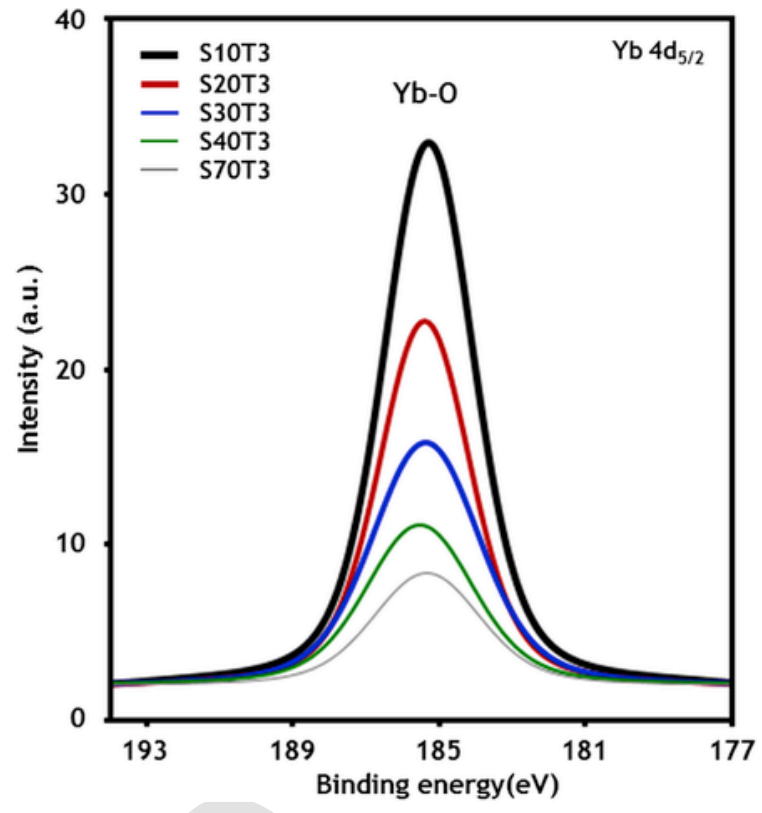

Fig. 3. $\mathrm{Yb} 4 \mathrm{~d}_{5 / 2}$ XPS spectra of $\mathrm{Yb}$ :ZTO films as a function of $\mathrm{Yb}$ :Sn sputtering power.

Nd:YAG laser. These are shown in Fig. 4. The strong and sharp peaks detected at $355 \mathrm{~nm}$ and $710 \mathrm{~nm}$ correspond to the laser source. A very weak intensity observed from the S10T3 sample near $380 \mathrm{~nm}$ in the UV region may result from band-to-band transitions. The broad peaks in the range of $500-850 \mathrm{~nm}$ of the visible light region identified from most of the samples are believed to be produced mainly by defect states. Even though their origin is still controversial, they are presumably associated with intrinsic defects such as oxygen vacancies and interstitial atoms [28]. For the S20T3 sample, a sharp and strong peak was detected near $975 \mathrm{~nm}$; it is presumably associated with the radiative transition of the ${ }^{2} \mathrm{~F}_{5 / 2}$ excited state to the ${ }^{2} \mathrm{~F}_{7 / 2}$ ground state of the $\mathrm{Yb}^{3+}$ ion. A satellite broad peak located at about $1010 \mathrm{~nm}$ is considered energy level splitting induced by the Stark effect in the $\mathrm{Yb}$ level. A similar observation was reported by Balestrieri et al. who studied a $\mathrm{ZnO}$ thin film Yb-doped by reactive sputtering [17]. The $\mathrm{Yb}$ characteristic peak near $975 \mathrm{~nm}$ was also found in the S30T3 sample

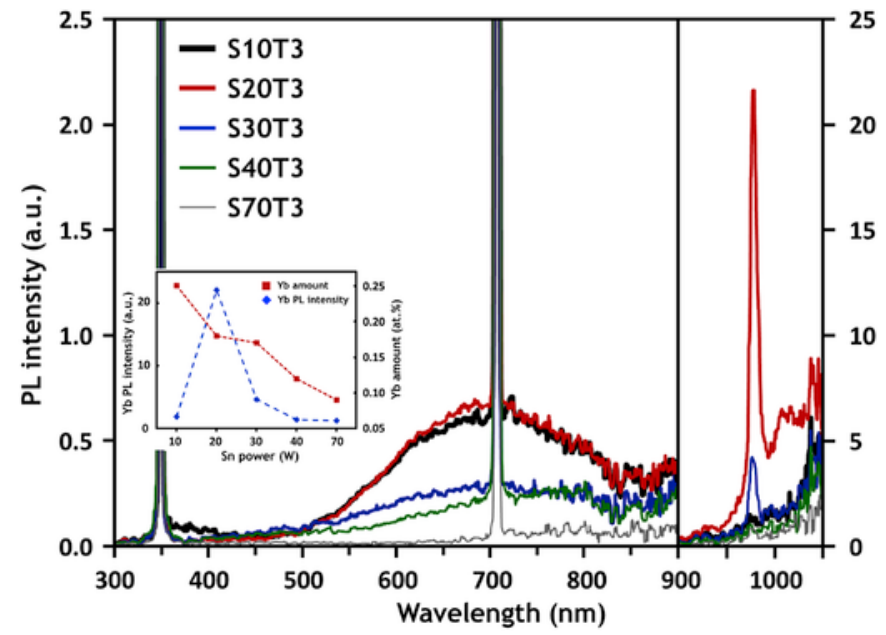

Fig. 4. PL spectra of $\mathrm{Yb}: \mathrm{ZTO}$ films at different $\mathrm{Sn}$ sputtering power. 
with a relatively weak intensity, but not detected in the other samples (S30T3 to S70T3) prepared with higher Sn sputtering power.

A more detailed comparison of peaks in the visible light region revealed that the peak intensity of the S10T3 and S20T3 samples was highest and similar to each other, and the intensity of the others decreased with increased Sn incorporation. This peak attenuation can be explained by several contributions. Firstly, the increase of Sn concentration reduces the crystallinity of ZTO, as shown in Fig. 2, and atomic disorder in an amorphous compound can produce the defect states causing non-radiative recombination [30,31]. Similarly, Karmakar et al. reported that the disorder introduced in a Mn-doped $\mathrm{ZnO}$ thin film led to the decrease of crystallinity and PL intensity [30]. In our study, as the Sn concentration increases, the more amorphous condition of the ZTO thin film can generate a dangling bond state yielding the competitive pathways for transitions between energy levels, and thus restricting PL emission in the visible light region, as schematically represented in Fig. 5. Secondly, the higher Sn incorporation into the ZTO structure increases oxygen concentration in ZTO as well, and reduces oxygen vacancies, which are usually responsible for the PL process. Lastly, it is assumed that the expansion in the energy band gap of the ZTO film with increased Sn concentration can limit the band-to-band excitation causing the reduction of PL intensity. For example, the estimated energy band gap of the S30T3 and S40T3 samples (S30T3: $3.80 \mathrm{eV}, \mathrm{S} 40 \mathrm{~T} 3: 3.70 \mathrm{eV}$ ) is larger than that of the laser $(3.49 \mathrm{eV} \cong 355 \mathrm{~nm})$ and thus the excitation from valence band to conduction band can be decreased. The drastic decrease of peak intensity in the S30T3 sample (with the highest band gap $\sim 3.8 \mathrm{eV}$ ) may be due to this reason.

As shown in Fig. 6, the S40T3 and S70T3 samples have a decreased band gap and increased oxygen vacancy, but showed lower PL intensity compared with S30T3, which suggests that the increased density of the dangling bond defect from an amorphous structure restricts the energy transfer. In general, the O1s peak can be deconvoluted into three peaks; a peak with the highest binding energy $(\sim 532.3 \mathrm{eV})$ corresponds to oxygen in hydroxide, and one with middle energy $(\sim 531.7 \mathrm{eV})$ is for oxygen in an oxygen deficient region. The peak with the lowest energy $(\sim 530.3 \mathrm{eV})$ belongs to

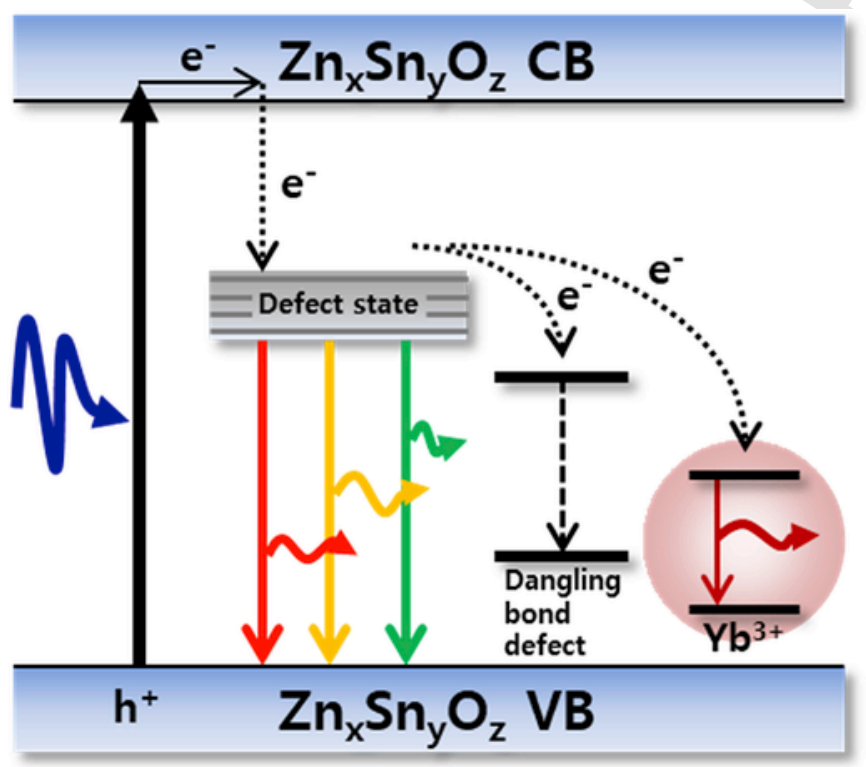

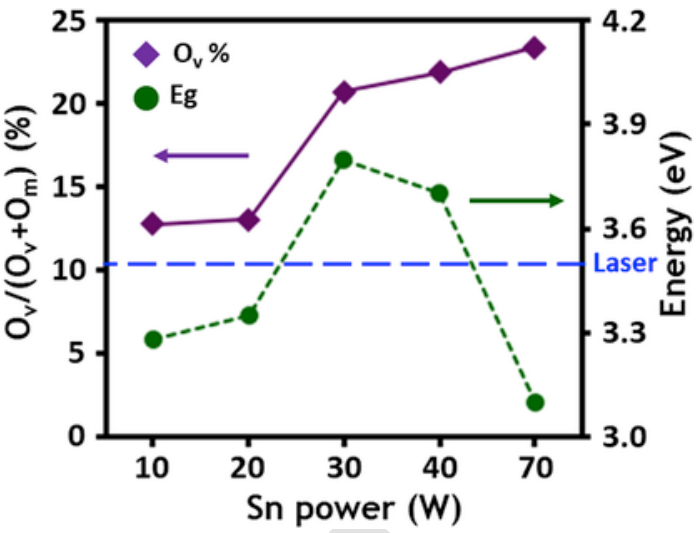

Fig. 6. Ratio of oxygen vacancy concentration estimated by O1s XPS spectra, and band gap energy (Eg) calculated by transmittance for $\mathrm{Yb}$ :ZTO films as a function of $\mathrm{Sn}$ sputtering power.

oxygen surrounded by $\mathrm{Zn}$ and $\mathrm{Sn}$ atoms. In this study, it was confirmed that O1s XPS spectra of all Yb:ZTO films were deconvoluted into only two characteristic peaks. The $\mathrm{O}_{\mathrm{m}}$ peak near low binding energy is commonly related to oxygen binding with metal such as $\mathrm{Zn}$, $\mathrm{Sn}$ atom, and the $\mathrm{O}_{\mathrm{V}}$ peak near high binding energy is to oxygen in an oxygen deficient region [32]. The $\mathrm{O}_{\mathrm{V}} /\left(\mathrm{O}_{\mathrm{m}}+\mathrm{O}_{\mathrm{V}}\right)$ ratio with $\mathrm{Sn}$ sputtering power is shown in Fig. 6. However, the lowest peak intensity was similarly observed from S70T3 samples having a lower energy band gap (S70T3: $3.10 \mathrm{eV}$ ) than the laser, which suggests that the effect of the band gap on the attenuation of the PL peak may not be dominant.

The $\mathrm{Yb}$ peak at $975 \mathrm{~nm}$ had the highest intensity in sample S20T3, and the intensity drastically decreased with increased Sn amount (S30T3 to S70T3). However, the sample with the smallest Sn amount (S10T3) showed much lower intensity compared with S20T3 presumably due to a concentration quenching effect. When the amount of optically active rare-earth ions increases to a certain level, the excitation energy is not transferred through a radiative transfer mechanism any longer; instead, it is transferred non-radiatively between dopant ions resulting in a reduced luminescence efficiency. Similar concentration quenching effects were also reported by other research groups in studies on Tb-doped $\mathrm{SnO}_{2}$ [33] and Nd-doped $\mathrm{SnO}_{2}$ [34] thin films. The attenuation of the $\mathrm{Yb}$ characteristic PL peak with increased Sn concentration can be attributed to the following reasons. Firstly, as similarly observed in the visible light region, more $\mathrm{Sn}$ incorporation into ZTO tends to increase the amorphous nature of the host compound and, thus, the density of dangling bond states to capture carriers, thereby restricting energy transfer from host to $\mathrm{Yb}$ ions. Secondly, the reduced density of internal defect states with increased Sn concentration can limit the PL efficiency of $\mathrm{Yb}$, as illustrated in Fig. 5. It has been reported that the intrinsic or extrinsic defect states of the host material can enhance the energy transfer from the host to the rare earth ions [35]. Salarie et al. tried to enhance light emission using cooperative transitions with defect states produced by oxygen vacancies in the host material [36]. Thirdly, the reduced Yb amount with increased Sn concentration as analyzed by XPS (Table 1) might be another reason for the reduced $\mathrm{Yb}$ PL intensity. However, considering the small difference of $\mathrm{Yb}$ concentration, the effect of variation in the energy states of host materials, such as defect states and dangling bond states, will be more dominant than that of $\mathrm{Yb}$ concentration.

The PL results in Fig. 4 suggest that the down-conversion effect has been confirmed by the PL emission in both visible light and the near-infrared (NIR) region with the $355 \mathrm{~nm}$ incident UV laser. In ad-

Fig. 5. Schematic energy band diagram of absorption and emission transitions in Yb:ZTO. 
dition, it should be noted that the scale of the $\mathrm{y}$-axis for the Yb peak (at $975 \mathrm{~nm}$ ) is 10 times larger than that for the peak in the visible light region, thus illustrating that the NIR PL emission of the $\mathrm{Yb}$ peak is much stronger than that in visible light. This suggests that ZTO can be a good host material for efficient energy transfer, and $\mathrm{Yb}$ light with a wavelength of $975 \mathrm{~nm}(\sim 1.27 \mathrm{eV})$ may be applicable for a CIGS-based $(\mathrm{Eg} \sim 1.2 \mathrm{eV})$ thin film solar cell.

The optical transmittance of Yb:ZTO thin films prepared onto glass substrates was investigated in the range of $300-1300 \mathrm{~nm}$ wavelength. As shown in Fig. 7, most films, notably except S70T3, exhibited considerable transmittance of over $80 \%$ in the visible region. With the increase of Sn sputter power from $10 \mathrm{~W}$ to $30 \mathrm{~W}$, the left absorption edge of the curve, i.e., the shortest wavelength region, shifted toward the left while it moved to the opposite direction with further increase of Sn sputter power from $30 \mathrm{~W}$ to $70 \mathrm{~W}$. The left shift of the absorption edge with increased Sn sputter power (10-30 W) may be attributed to the increased energy band gap by the Burstein-Moss effect [37]; that is, the energy band gap of ZTO increases by adding Sn as an electron donor because $\mathrm{Sn}$ has four valence electrons compared to $\mathrm{Zn}$ having two valence electrons. In contrast, the right shift of the absorption edge in the higher Sn sputter power $(30-70 \mathrm{~W})$ can be explained by structural properties. As shown in Fig. 2, the enhanced incorporation of Sn into ZTO films by increasing Sn sputter power can make ZTO films more amorphous; thus, this leads to the formation of a localized band tail state, due to the structural disorder, yielding a reduced band gap and lower transmittance [22].

As shown in the inset of Fig. 7, the energy band gap of ZTO films was estimated by using the Tauc plots [38] based on the absorption edge of the transmittance curve, assuming the direct transition between valence and conduction bands. The estimated values of the energy band gap were in the range of $3.10-3.80 \mathrm{eV}$, which is similar to those reported by other research groups [37,39]. Young et al. reported that crystalline ZTO thin films deposited by the sputtering technique showed a direct optical band gap in the range 3.3-3.9eV, which was influenced by Burstein-Moss shift effect and structural dissimilarity of the ZTO thin films [37]. As mentioned in the previous paragraph, the band gap became wider with increased Sn sputter power from 10 to $30 \mathrm{~W}(\mathrm{Eg}=3.28-3.80 \mathrm{eV})$, and then reduced with further increase from 30 to $70 \mathrm{~W}(\mathrm{Eg}=3.80$ to $3.10 \mathrm{eV})$.

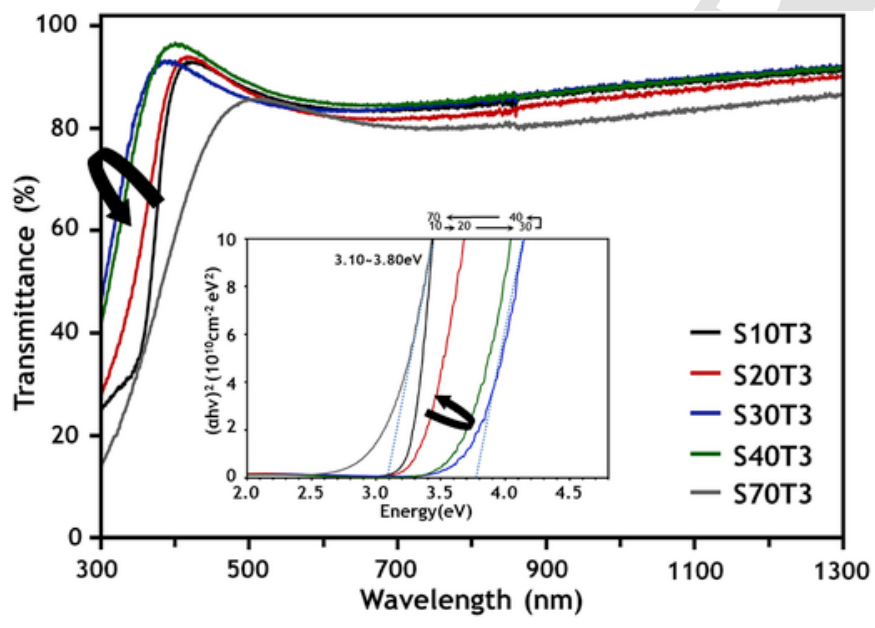

Fig. 7. UV-vis-NIR optical transmittance of Yb:ZTO thin films for different Sn sputtering power, and corresponding energy band gaps estimated by Tauc plot (inset).

\subsection{Effect of substrate temperature}

It has been reported that the deposition temperature has a strong influence on photoluminescence of rare-earth atoms in host materials such as $\mathrm{ZnO}$ and $\mathrm{SnO}_{2}[10,17]$. To investigate the effect of substrate temperature during the sputtering process of $\mathrm{Yb}: \mathrm{ZTO}$, the substrate temperature was varied from 100 to $400{ }^{\circ} \mathrm{C}$ while the sputtering power of $\mathrm{Zn}$ and $\mathrm{Sn}$ were held constant at $70 \mathrm{~W}$ and $20 \mathrm{~W}$, respectively. Considering the subsequent fabrication of working solar cells, the maximum temperature was limited to $400^{\circ} \mathrm{C}$.

The structural and compositional properties of $\mathrm{Yb}: \mathrm{ZTO}$ films were investigated by GI-XRD and XPS analyses. The results of the GI-XRD, shown in Fig. 8, revealed that there is no significant difference in shape and intensity of the characteristic ZTO peak at $2 \theta=32-34^{\circ}$, which is not strong and thus nearly amorphous. It has also been reported that ZTO films maintain an amorphous nature up to $500-600^{\circ} \mathrm{C}[40,41]$. Choi et al. suggested that the stability of the amorphous ZTO phase below $600^{\circ} \mathrm{C}$ is attributed to the immiscible system of pseudo-binary $\mathrm{ZnO}$ and $\mathrm{SnO}_{2}$ [41]. As temperature increased from 100 to $400^{\circ} \mathrm{C}$, the characteristic peak of ZTO near $2 \theta=32-34^{\circ}$ shifted slightly to a lower $2 \theta$ position, presumably due to atomic rearrangement. It can be assumed that the increased temperature can supply thermal energy for further rearrangement of atoms within the amorphous structure. Furthermore, higher temperature can cause atomic vacancies to be occupied, thus yielding the lattice expansion and the left shift of XRD peak. The composition estimated by XPS spectra of the Yb:ZTO films prepared at different substrate temperature, i.e., the deposition temperature, is summarized in Table 2. The overall composition of $\mathrm{Sn} /(\mathrm{Zn}+\mathrm{Sn})$ for thin films deposited at a substrate temperature in the range of $100-400{ }^{\circ} \mathrm{C}$ was $0.239-0.253$, indicating nearly a stoichiometric $\mathrm{Zn}_{3} \mathrm{SnO}_{4}$ ternary phase.

As shown in Fig. 9 and summarized in Table 2, the incorporation of $\mathrm{Yb}$ into ZTO decreased at the highest substrate temperature of

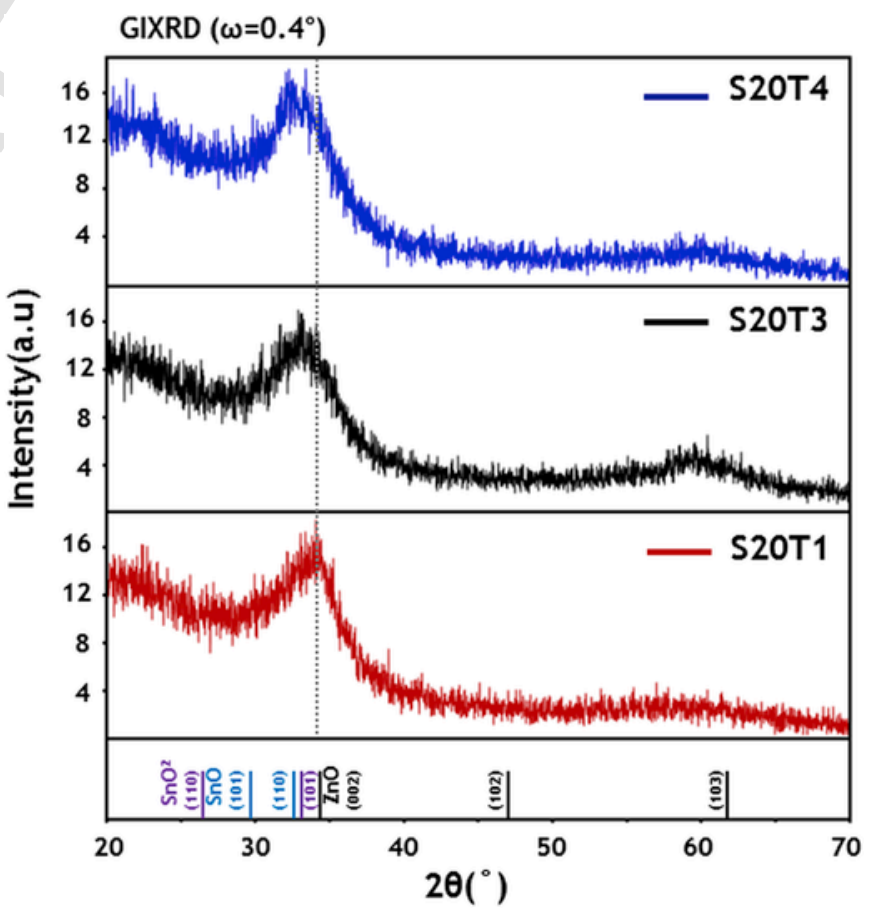

Fig. 8. GI-XRD patterns of the Yb:ZTO thin films deposited at different substrate temperatures: $100^{\circ} \mathrm{C}(\mathrm{T} 1), 300{ }^{\circ} \mathrm{C}(\mathrm{T} 3)$, and $400^{\circ} \mathrm{C}(\mathrm{T} 4)$. 
Table 2

Composition estimated by XPS spectra of Yb:ZTO films deposited at different substrate temperatures.

\begin{tabular}{|c|c|c|c|c|c|c|c|c|}
\hline Sample & $\begin{array}{l}\text { Substrate } \\
\text { Temp. }\left({ }^{\circ} \mathrm{C}\right)\end{array}$ & Zn 2p (at.\%) & Sn 3d (at. \%) & $\mathrm{Sn} /(\mathrm{Zn}+\mathrm{Sn})$ & O 1s (at.\%) & $\mathrm{Zn}: \mathrm{Sn}: \mathrm{O}$ & Yb 4d (at.\%) & Band gap (eV) \\
\hline S20T4 & 400 & 37.6 & 12.4 & 0.248 & 49.9 & $3(+0.03): 1: 4(+0.02)$ & 0.16 & 4.00 \\
\hline S20T3 & 300 & 40.8 & 12.8 & 0.239 & 46.2 & $3(+0.18): 1: 4(-0.40)$ & 0.18 & 3.33 \\
\hline S20T1 & 100 & 39.6 & 13.4 & 0.253 & 46.7 & $3(+0.05): 1: 4(-0.53)$ & 0.18 & 3.45 \\
\hline
\end{tabular}

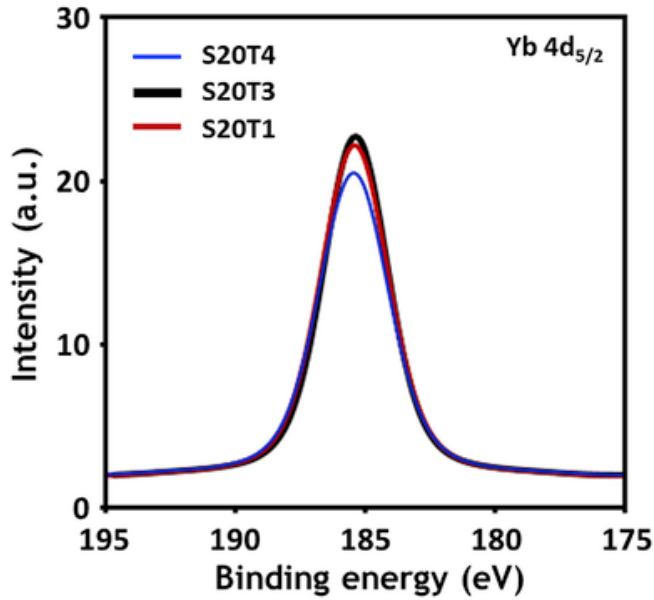

Fig. 9. $\mathrm{Yb} 4 \mathrm{~d}_{5 / 2}$ XPS spectra of $\mathrm{Yb}$ :ZTO films deposited at different substrate temperatures: $100^{\circ} \mathrm{C}(\mathrm{T} 1), 300^{\circ} \mathrm{C}(\mathrm{T} 3)$, and $400^{\circ} \mathrm{C}(\mathrm{T} 4)$.

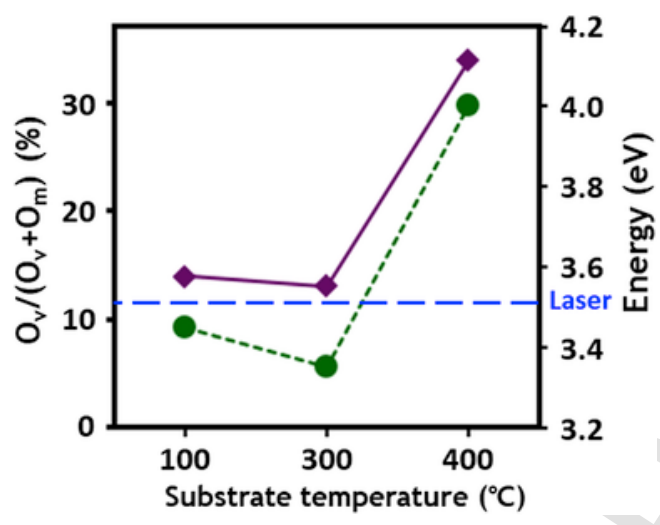

Fig. 10. Ratio of oxygen vacancy concentration (diamonds) estimated by O1s XPS spectra and band gap (circles) calculated by transmittance for Yb:ZTO films deposited at different substrate temperatures: $100^{\circ} \mathrm{C}(\mathrm{T} 1), 300^{\circ} \mathrm{C}(\mathrm{T} 3)$ and $400{ }^{\circ} \mathrm{C}(\mathrm{T} 4)$.

$400^{\circ} \mathrm{C}$, compared to $100^{\circ} \mathrm{C}$ and $300^{\circ} \mathrm{C}$. This can be explained by the decrease of available doping sites in the ZTO host because the atomic rearrangement of active $\mathrm{Zn}$ and $\mathrm{Sn}$ atoms is enhanced at high temperature, the doping sites are preoccupied. Therefore, it can be assumed that a too-high temperature may not be beneficial to the incorporation of $\mathrm{Yb}$ into the ZTO compound under a crystallization phase, due to its immiscible nature (see Fig. 10).

As displayed in Fig. 11, PL measurements have been carried out to investigate the effect of deposition temperature on the photoluminescence properties of $\mathrm{Yb}: \mathrm{ZTO}$ films. Apparently, an increase in temperature from 100 to $400{ }^{\circ} \mathrm{C}$ did not generate new peaks in the measured wavelength range of $300-1050 \mathrm{~nm}$. As temperature increased from 100 to $400{ }^{\circ} \mathrm{C}$, the defect band near the visible light region decreased. The intensity of the $\mathrm{Yb}$ PL peak at $975 \mathrm{~nm}$ was also reduced. This decrease in visible emission can be explained by sev-

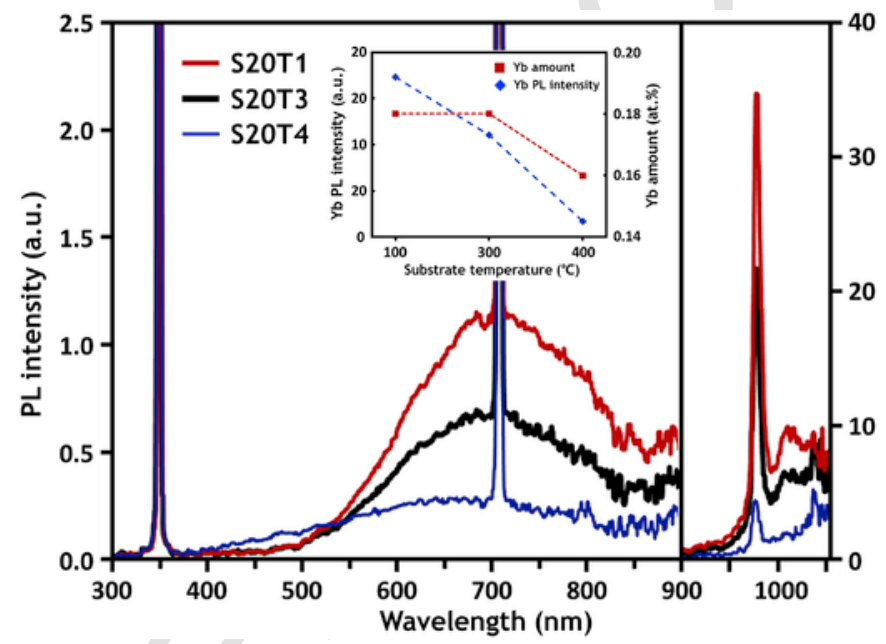

Fig. 11. PL spectra of $Y b: Z T O$ films deposited at different substrate temperatures.

eral contributions. As indicated in the previous XPS result, oxygen vacancies, which induce visible PL emission, were decreased at $300^{\circ} \mathrm{C}$, and thus the PL intensity decreased as well. In addition, the area of grain boundaries increased, due to the formation of $\mathrm{ZnO}$ grains. The grain boundaries usually cause non-radiative recombination; thus radiative emission was relatively decreased [42]. The significant decrease at $400^{\circ} \mathrm{C}$ may be attributed to the high band gap of the film $(\sim 4.0 \mathrm{eV})$, which is larger than the laser excitation energy, thus reducing the excitation from the valence band. This increase in band gap will be discussed further in the next section. The decrease in the intensity of $\mathrm{Yb} \mathrm{PL}$ emission is proportional to the amount of electrons in radiative defect transition. At $300^{\circ} \mathrm{C}$, while the number of excited electrons might be larger than that at $100^{\circ} \mathrm{C}$, due to a decreased band gap, it seems that energy transfer to the $\mathrm{Yb}$ atoms decreased because of a non-radiative defect center. At $400^{\circ} \mathrm{C}$, the number of excited electrons decreased further, resulting in the decreased transfer to the $\mathrm{Yb}$ atoms. Furthermore, the decreased number of $\mathrm{Yb}$ atoms at $400{ }^{\circ} \mathrm{C}$ could contribute to the decreased PL emission of $\mathrm{Yb}$. The PL results indicate that despite the same number of $\mathrm{Yb}$ ions in the film, the properties of the ZTO host strongly influence its PL emission. From the PL measurement, a high PL emission is favorable in the ZTO host at a relatively low temperature within the amorphous state.

To investigate the effect of deposition temperature on transmittance of Yb:ZTO films, the transmittance was measured in the $300-1300 \mathrm{~nm}$ range, as displayed in Fig. 12. The values of the corresponding energy band gap were extracted by using a Tauc plot as in the figure inset. The transmittance of films with the deposition temperature of $100-400{ }^{\circ} \mathrm{C}$ showed over $80 \%$ in the entire wavelength region. It was revealed that the energy band gap of Yb:ZTO film slightly decreased $(3.45-3.33 \mathrm{eV})$ or remained the same as the deposition temperature was raised from 100 to $300^{\circ} \mathrm{C}$, but it noticeably increased up to $4.0 \mathrm{eV}$ as temperature reached $400^{\circ} \mathrm{C}$. This dramatic increase might be attributed to the increased oxygen vacancies with 


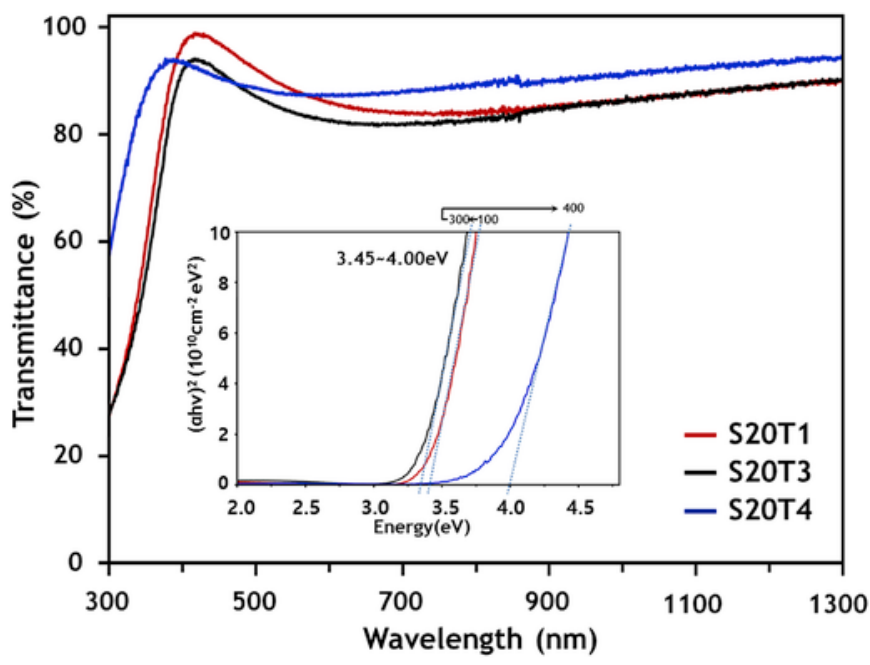

Fig. 12. UV-vis-NIR optical transmittance of Yb:ZTO thin films for different deposition temperatures, and corresponding energy band gaps estimated by Tauc plot (inset).

increased temperature. It was reported that oxygen vacancies in a TCO thin film act as donor-producing excess carriers, changing the energy band gap by means of the Burstein-Moss (BM) effect [43]. In addition, the increase in band gap of $\mathrm{Yb}: \mathrm{ZTO}$ at a deposition temperature of $400{ }^{\circ} \mathrm{C}$ resulted in the shift of the transmittance plot to the low wavelength region, as coincidently shown in Fig. 12. It is well known that high deposition temperatures in semiconductor thin films can produce oxygen deficient films $[43,44]$. This is because oxygen desorption occurs in metal oxide materials at high temperatures due to the low formation energy of oxygen vacancies. At $300^{\circ} \mathrm{C}$, however, the formation of oxygen vacancies was restricted, presumably due to the formation of $\mathrm{ZnO}$.

\subsection{Application to solar cells}

Based on the above study of ZTO properties by changing Sn sputter power and substrate temperature during co-sputtering of $\mathrm{Sn}$ and $\mathrm{Zn}$ in a flowing oxygen environment, we determined the potentially optimized conditions of $15 \mathrm{~W} \mathrm{Sn}$ sputter power and $100^{\circ} \mathrm{C}$ substrate temperature. These conditions were employed to deposit another set of Yb:ZTO films. As shown in Fig. 13, the Yb PL peak intensity of the $\mathrm{Yb}: Z T O$ film deposited at these sputtering conditions is greater than those of the other films in the study, suggesting better energy transfer efficiency. Therefore, these sputtering conditions were employed to deposit an Yb:ZTO film for the fabrication of a glass/Mo/CIGS/ $\mathrm{CdS} / \mathrm{Yb}: Z T O: A Z O$ solar cell. The current-voltage characteristics of this cell are compared with those of a conventional glass/Mo/CIGS/ $\mathrm{CdS} / \mathrm{i}-\mathrm{ZnO} / \mathrm{AZO}$ solar cell in Fig. 14. It is interesting to note that the overall cell efficiency of CIGS cell with Yb:ZTO $(\eta=10.3 \%)$ is nearly equivalent to that of a conventional CIGS cell with $\mathrm{i}-\mathrm{ZnO}(\eta=11.2 \%)$. It seems that the slight increase in Jsc and Voc of the Yb:ZTO-CIGS cell was offset by the loss of fill factor (i.e., 51.2\%-45.7\%). Slight increase of $\mathrm{V}_{\mathrm{OC}}$ (i.e., $0.568-0.574 \mathrm{~V}$ ) might be resulted from the increase of shunt resistance $\left(\mathrm{R}_{\mathrm{SH}}\right)$ (i.e., 648 to $\left.771 \Omega \mathrm{cm}^{2}\right)$. The improved Jsc $\left(38.5-39.2 \mathrm{~mA} / \mathrm{cm}^{2}\right)$ can be explained by down-conversion effect of $\mathrm{Yb}: \mathrm{ZTO}$ layer leading to more absorption and collection of photons demonstrated by EQE results later.

The external quantum efficiency plot of Fig. 15 confirmed that the Yb:ZTO-CIGS cell demonstrated enhanced quantum efficiency, com-

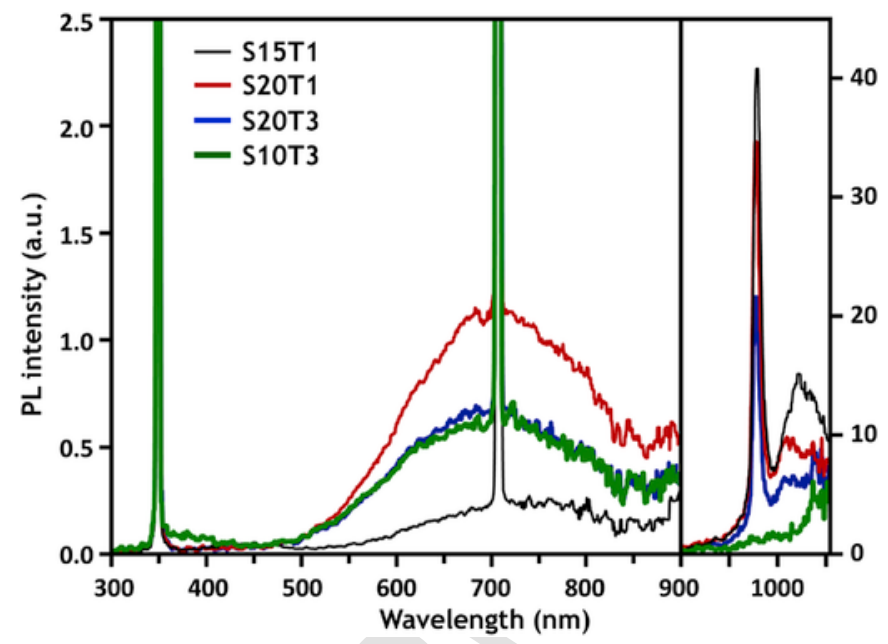

Fig. 13. PL spectra of $\mathrm{Yb}$ :ZTO films deposited at different sputter conditions: Sn sputter power of $10,15,20 \mathrm{~W}$ and substrate temperature of 100 and $300^{\circ} \mathrm{C}$.

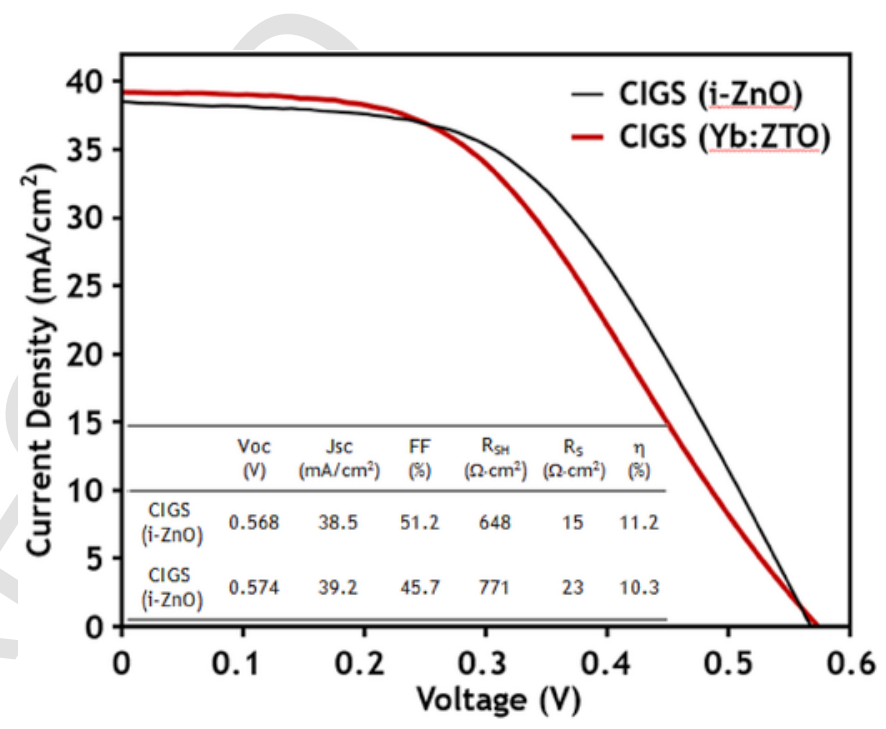

Fig. 14. Current-voltage characteristics of Yb:ZTO-incorporated CIGS solar cell and reference $(\mathrm{i}-\mathrm{ZnO})$ cell.

pared to the conventional i-ZnO-CIGS cell. This is particularly so in the UV region (inset of Fig. 15), presumably because of the photon conversion effect. To make sure that the increase of quantum efficiency was due to the down-conversion effect but not the increased light absorption, the absorption by the $\mathrm{Yb}$ :ZTO and i-ZnO layers was compared by means of reflectance and transmittance measurements. It was observed that the reflectance and transmittance of the Yb:ZTO films were greater than those of i-ZnO film (see Supporting Data), thus supporting the claim that the enhanced quantum efficiency was not caused primarily by increased light absorption. It was also confirmed that the conductivity of a film was not improved by adopting $\mathrm{Yb}: Z T O$, as noticed by the crossover of the EQE plot at the wavelength of $900-1000 \mathrm{~nm}$. Therefore, the detailed study on the other reasons for enhanced EQE suggested that the Yb:ZTO layer acts as a photon converter. Further optimization of $\mathrm{Yb}$ doping, such as $\mathrm{Yb}$ concentration, deposition temperature, and film thickness may improve the optoelectronic properties of the $\mathrm{Yb}: \mathrm{ZTO}$ film and the corresponding CIGS device performance. 


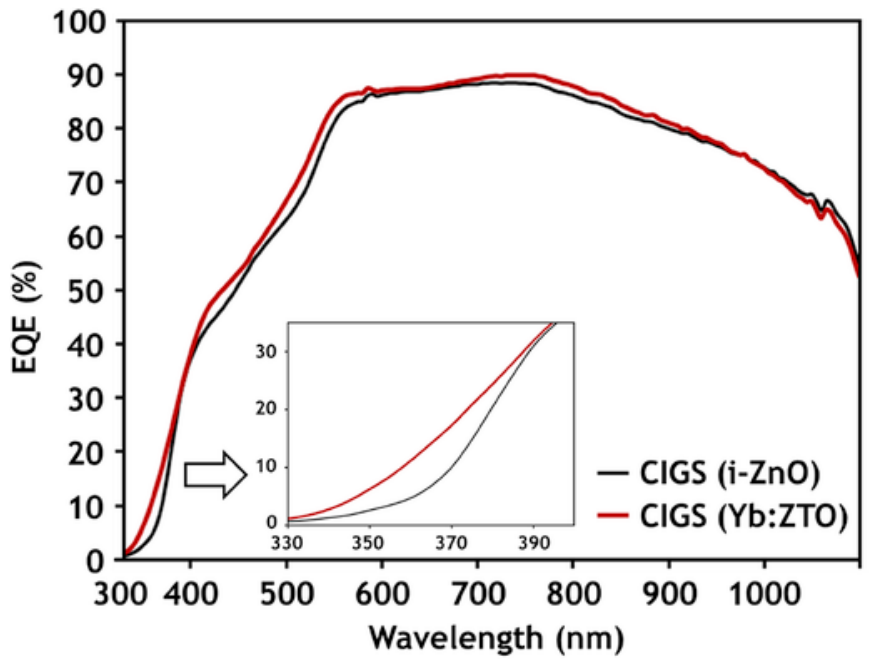

Fig. 15. External quantum efficiency plot for $\mathrm{Yb}$ :ZTO incorporated CIGS solar cell and reference (i-ZnO) CIGS cell.

\section{Conclusion}

$\mathrm{Yb}: \mathrm{ZTO}$ films were prepared by reactive co-sputtering of $\mathrm{Yb}: \mathrm{Zn}$ and Sn targets, and their crystallographic and optoelectronic properties were thoroughly investigated by changing Sn sputtering power $(10-70 \mathrm{~W})$ to determine ZTO composition, and substrate temperature $\left(100-400^{\circ} \mathrm{C}\right)$. It was demonstrated that $\mathrm{Yb}$ PL emission is significantly affected by the defect state in the ZTO host; it can be controlled by the amount of Sn in the ZTO and the substrate temperature during deposition. The results of the PL analysis suggested that the efficiency of energy transfer from host to $\mathrm{Yb}$ ions was highest for a sample prepared at a substrate temperature of $100^{\circ} \mathrm{C}$, in the range of $100-400^{\circ} \mathrm{C}$. As this study shows, the highest performance $\mathrm{Yb}: \mathrm{ZTO}-\mathrm{CIGS}$ solar cell has been fabricated by adopting Yb:ZTO deposited at the suggested optimum conditions of $15 \mathrm{~W} \mathrm{Sn}$ sputter power and $100^{\circ} \mathrm{C}$ substrate temperature. The potential photon converting effect of $\mathrm{Yb}: \mathrm{ZnO}$ film was supported by the observation of increased quantum efficiency without an increase of light absorption.

\section{Acknowledgment}

This study was supported by Priority Research Centers Program through the National Research Foundation of Korea (NRF) funded by the Ministry of Education (2014R1A6A1031189) and "Human Resources Program in Energy Technology" of the Korea Institute of Energy Technology Evaluation and Planning (KETEP), granted financial resource from the Ministry of Trade, Industry \& Energy, Republic of Korea. (No. 20174030201760).

\section{Appendix A. Supplementary data}

Supplementary data to this article can be found online at https:// doi.org/10.1016/j.jallcom.2019.152360.

\section{References}

[1] A. Colthorpe, Solar Frontier Achieves CIS Thin-Film Lab Efficiency Record of 23.35\%, 2019 https://www.pv-tech.org/news/solar-frontier-achieves-cis-thinfilm-efficiency-record-of-23.35, Accessed 1 February 2019, accessed.
[2] M.A. Green, Y. Hishikawa, E.D. Dunlop, D.H. Levi, J.H. Ebinger, M. Yoshita, A.W.Y. Ho-Baillie, Solar cell efficiency tables (Version 53), Prog. Photovolt. Res. Appl. 27 (2019) 3-12 https://doi.org/10.1002/pip.3102.

[3] D. Lee, K. Yong, Non-vacuum deposition of CIGS absorber films for low-cost thin film solar cells, Korean J. Chem. Eng. 30 (2013) 1347-1358 https://doi.org/ 10.1007/s11814-013-0101-0.

[4] V.B. Chu, S.J. Park, G.S. Park, H.S. Jeon, Y.J. Hwang, B.K. Min, Semi-transparent thin film solar cells by a solution process, Korean J. Chem. Eng. 33 (2016) 880-884 https://doi.org/10.1007/s11814-015-0200-1.

[5] S.K. Lee, H.J. Jeong, Y.C. Kim, J.H. Jang, Improvement in CIGS solar cell efficiency using a micro-prism array integrated with sub-wavelength structures, Sol. Energy Mater. Sol. Cells 186 (2018) 254-258 https://doi.org/10.1016/j.solmat. 2018.06.045.

[6] R.L. Garris, S. Johnston, J.V. Li, H.L. Guthrey, K. Ramanathan, L.M. Mansfield, Electrical characterization and comparison of CIGS solar cells made with different structures and fabrication techniques, Sol. Energy Mater. Sol. Cells 174 (2018) 77-83 https://doi.org/10.1016/j.solmat.2017.08.027.

[7] P.M.P. Salomé, J. Keller, T. Törndahl, J.P. Teixeira, N. Nicoara, R.-R. Andrade, D.G. Stroppa, J.C. González, M. Edoff, J.P. Leitão, S. Sadewasser, CdS and Zn1- xSnxOy buffer layers for CIGS solar cells, Sol. Energy Mater. Sol. Cells 159 (2017) 272-281 https://doi.org/10.1016/j.solmat.2016.09.023.

[8] D. Chen, Y. Wang, M. Hong, Lanthanide nanomaterials with photon management characteristics for photovoltaic application, Nano Energy 1 (2012) 73-90 https://doi.org/10.1016/j.nanoen.2011.10.004.

[9] K. Bouras, J.-L. Rehspringer, G. Schmerber, H. Rinnert, S. Colis, G. Ferblantier, M. Balestrieri, D. Ihiawakrim, A. Dinia, A. Slaoui, Optical and structural properties of $\mathrm{Nd}$ doped $\mathrm{SnO}_{2}$ powder fabricated by the sol-gel method, J. Mater. Chem. C. 2 (2014) 8235-8243 http://doi.org/10.1039/C4TC01202J.

[10] K. Bouras, G. Schmerber, H. Rinnert, D. Aureau, H. Park, G. Ferblantier, S. Colis, T. Fix, C. Park, W.K. Kim, A. Dinia, A. Slaoui, Structural, optical and electrical properties of $\mathrm{Nd}$-doped $\mathrm{SnO}_{2}$ thin films fabricated by reactive magnetron sputtering for solar cell devices, Sol. Energy Mater. Sol. Cells 145 (2016) 134-141 https://doi.org/10.1016/j.solmat.2015.07.038.

[11] D. Verma, T.O. Saetre, O.-M. Midtgård, Review on up/down conversion materials for solar cell application, Proc. 38th IEEE Photovolt. Spec. Conf. (2012) 2608-2613, https://doi.org/10.1109/PVSC.2012.6318129.

[12] H. Park, S. Alhammadi, K. Bouras, G. Schmerber, G. Ferblantier, A. Dinia, A. Slaoui, C.-W. Jeon, C. Park, W.K. Kim, Nd-Doped $\mathrm{SnO}_{2}$ and $\mathrm{ZnO}$ for application in $\mathrm{Cu}(\mathrm{InGa}) \mathrm{Se}_{2}$ solar cells, Sci. Adv. Mater. 9 (2017) 2114-2120 https://doi. org/10.1166/sam.2017.3207.

[13] Y. Liu, W. Luo, R. Li, H. Zhu, X. Chen, Near-infrared luminescence of $\mathrm{Nd}^{3+}$ and $\mathrm{Tm}^{3+}$ ions doped $\mathrm{ZnO}$ nanocrystals, Opt. Express 17 (2019) 9748-9753 https:// doi.org/10.1364/OE.17.009748.

[14] Y.-P. Du, Y.-W. Zhang, L.-D. Sun, C.-H. Yan, Efficient energy transfer in monodisperse Eu-doped $\mathrm{ZnO}$ nanocrystals synthesized from metal acetylacetonates in high-boiling solvents, J. Phys. Chem. C 112 (2008) 12234-12241 https: //doi.org/10.1021/jp802958x.

[15] H. Li, K. Luo, M. Xia, P.W. Wang, Synthesis and optical properties of $\mathrm{Pr}^{3+}$-doped $\mathrm{ZnO}$ quantum dots, J. Non-Cryst. Solids 383 (2014) 176-180 https:// doi.org/10.1016/j.jnoncrysol.2013.04.028.

[16] Y. Bai, Y. Wang, K. Yang, X. Zhang, Y. Song, C.H. Wang, Enhanced upconverted photoluminescence in $\mathrm{Er}^{3}+$ and $\mathrm{Yb}^{3+}$ codoped $\mathrm{ZnO}$ nanocrystals with and without $\mathrm{Li}^{+}$ions, Opt. Commun. 281 (2018) 5448-5452 https://doi.org/10.1016/ j.optcom.2008.07.041.

[17] M. Balestrieri, G. Ferblantier, S. Colis, G. Schmerber, C. Ulhaq-Bouillet, D. Muller, A. Slaoui, A. Dinia, Structural and optical properties of Yb-doped ZnO films deposited by magnetron reactive sputtering for photon conversion, Sol. Energy Mater. Sol. Cells 117 (2013) 363-371 https://doi.org/10.1016/j.solmat. 2013.06.032.

[18] F. Gu, S.F. Wang, M.K. Lü, G.J. Zhou, D. Xu, D.R. Yuan, Structure evaluation and highly enhanced luminescence of $\mathrm{Dy}^{3+}$-doped $\mathrm{ZnO}$ nanocrystals by $\mathrm{Li}^{+}$doping via combustion method, Langmuir 20 (2004) 3528-3531 https://doi.org/10. 1021/la049874f

[19] H. Bastami, E. Taheri-Nassaj, Synthesis of nanosized (Co, Nb, Sm)-doped $\mathrm{SnO}_{2}$ powders using co-precipitation method, J. Alloy. Comp. 495 (2010) 121-125 https://doi.org/10.1016/j.jallcom.2010.01.099.

[20] P. Psuja, W. Strek, Influence of concentration and sintering temperature on luminescence properties of $\mathrm{Eu}^{3+}: \mathrm{SnO}_{2}$ nanocrystallites, J. Rare Earths 30 (2012) 627-631 https://doi.org/10.1016/S1002-0721(12)60102-1.

[21] T. Minami, H. Sonohara, S. Takata, H. Sato, Highly transparent and conductive zinc-stannate thin films prepared by RF magnetron sputtering, Jpn. J. Appl. Phys. 33 (1994) 1693-1696 http://doi.org/10.1143/JJAP.33.L1693.

[22] J.H. Ko, I.J. Kim, D. Kim, K.S. Lee, T.S. Lee, B. Cheong, W.M. Kim, Transparent and conducting $\mathrm{Zn}-\mathrm{Sn}-\mathrm{O}$ thin films prepared by combinatorial approach, Appl. Surf. Sci. 253 (2007) 7398-7403 https://doi.org/10.1016/j.apsusc.2007.03. 036 . 
[23] M. Dimitrievska, T.B. Ivetic, A.P. Litvinchuk, A. Fairbrother, B.B. Miljevic, G.R. Strbac, A.P. Rodriguez, S.R. Lukic-Petrovic, $\mathrm{Eu}^{3+}$ Doped wide band gap $\mathrm{Zn}_{2} \mathrm{SnO}_{4}$ semiconductor nanoparticles: structure and luminescence, J. Phys. Chem. C 120 (2016) 18887-18894 https://doi.org/10.1021/acs.jpcc.6b05335.

[24] T. Moriga, Y. Hayashi, K. Kondo, Y. Nishimura, K.-I. Murai, I. Nakabayashi, Transparent conducting amorphous $\mathrm{Zn}-\mathrm{Sn}-\mathrm{O}$ films deposited by simultaneous dc sputtering, J. Vac. Sci. Technol. A 22 (2004) 1705-1710 https://doi.org/10.1116/ 1.1765658 .

[25] G.A. Olatunji, A.T. Kola-Mustapha, O.D. Saliu, A.B. Alabi, O.I. Abiodun, N.O. Obisesan, Tramadol hydrochloride delivery by regenerated cellulose nanofiber- $\mathrm{TiO}_{2}-\mathrm{ZnO}$ composites, Korean J. Chem. Eng. 35 (2018) 784-791 https://doi.org/10.1007/s11814-017-0314-8.

[26] S. Sehar, I. Naz, I. Perveen, S. Ahmed, Superior dye degradation using $\mathrm{SnO}_{2}-\mathrm{ZnO}$ hybrid heterostructure catalysts, Korean J. Chem. Eng. 36 (2019) 56-62 https://doi.org/10.1007/s11814-018-0159-9.

[27] D. Briggs, Handbook of X-Ray Photoelectron Spectroscopy, Heyden, London, 1977.

[28] E. Flage-Larsen, S. Diplas, Ø. Prytz, E.S. Toberer, A.F. May, Valence band study of thermoelectric Zintl-phase $\mathrm{SrZn}_{2} \mathrm{Sb}_{2}$ and $\mathrm{YbZn}_{2} \mathrm{Sb}_{2}$ : X-ray photoelectron spectroscopy and density functional theory, Phys. Rev. B. 81 (1-7) (2010) 205204 https://doi.org/10.1103/PhysRevB.81.205204.

[29] Y.-B. Hahn, Zinc oxide nanostructures and their applications, Korean J. Chem. Eng. 28 (2011) 1797-1813 https://doi.org/10.1007/s11814-011-0213-3.

[30] P. Karmakar, S.K. Neogi, A. Barnrjee, S. Bandyopadhyay, Structural; morphological; optical and magnetic properties of Mn doped ferromagnetic $\mathrm{ZnO}$ thin film, Appl. Surf. Sci. 263 (2012) 671-677 https://doi.org/10.1016/j.apsusc.2012. 09.133.

[31] K. Pita, Q.V. Vu, in: Y. Masuda (Ed.), Energy Transfer from Silicon Nanocrystals to $\mathrm{Er}^{3+}$ Ions Embedded in Silicon Oxide Matrix, Nanocrysals, InTech, Croatia, 2011, pp. 437-458, https://doi.org/10.5772/17490.

[32] Y. Zhao, G. Dong, L. Duan, J. Qiao, D. Zhang, L. Wang, Y. Qiu, Impacts of Sn precursors on solution-processed amorphous zinc-tin oxide films and their transistors, RSC Adv. 2 (2012) 5307-5313 http://doi.org/10.1039/C2RA00764A.

[33] F. Hild, L. Eichenberger, A. Bouché, X. Devaux, M. Stoffel, H. Rinnert, M. Vergnat, Structural and photoluminescence properties of evaporated $\mathrm{SnO}_{2}$ thin films doped with rare earths, Energy. Procedia 84 (2015) 141-148 https://doi. org/10.1016/j.egypro.2015.12.307.

[34] H. Rinnert, P. Miska, M. Vergnat, G. Schmerber, S. Colis, A. Dinia, D. Muller, G. Ferblantier, A. Slaoui, Photoluminescence of Nd-doped $\mathrm{SnO}_{2}$ thin films, Appl. Phys. Lett. 100 (2012) 101908-101910 https://doi.org/10.1063/1.3692747.
[35] A. Layek, S. Banerjee, B. Manna, A. Chowdhury, Synthesis of rare-earth doped $\mathrm{ZnO}$ nanorods and their defect-dopant correlated enhanced visible-orange luminescence, RSC Adv. 6 (2016) 35892-35900 http://doi.org/10.1039/ C6RA02278B.

[36] S. Salari, F.E. Ghodsi, A significant enhancement in the photoluminescence emission of the $\mathrm{Mg}$ doped $\mathrm{ZrO}_{2}$ thin film by tailoring the effect of oxygen vacancy, J. Lumin. 182 (2017) 289-299 https://doi.org/10.1016/j.jlumin.2016.10. 035 .

[37] D.L. Young, H. Moutino, Y. Yan, T.J. Coutts, Growth and characterization of radio frequency magnetron sputter-deposited zinc stannate, $\mathrm{Zn}_{2} \mathrm{SnO}_{4}$ thin films, J. Appl. Phys. 92 (2002) 310-319 https://doi.org/10.1063/1.1483104

[38] J. Tauc, R. Grigorovici, A. Vancu, Phys. Status solidi, optical properties and electronic structure of amorphous germanium, Phys. Status Solidi 15 (1966) 627-637 https://doi.org/10.1002/pssb.19660150224.

[39] S.-W. Chang, K. Ishikawa, M. Sugiyama, Growth of amorphous Zn-Sn-O thin films by RF sputtering for buffer layers of $\mathrm{CuInSe}_{2}$ and $\mathrm{SnS}$ solar cells, Thin Solid Films 589 (2015) 408-411 https://doi.org/10.1016/j.tsf.2015.06.003.

[40] I.-J. Lee, N.-E. Sung, K.H. Chae, R. Conley, Characterization of zinc-tin-oxide films deposited by radio frequency magnetron sputtering at various substrate temperatures, Thin Solid Films 548 (2013) 385-388 https://doi.org/10.1016/j.tsf. 2013.08.067.

[41] Y.-Y. Choi, S.J. Kang, H.-K. Kim, Rapid thermal annealing effect on the characteristics of $\mathrm{ZnSnO}_{3}$ films prepared by RF magnetron sputtering, Curr. Appl. Phys. 12 (2012) S104-S107 https://doi.org/10.1016/j.cap.2012.05.014.

[42] T. Matsumoto, H. Kato, K. Miyamoto, M. Sano, E.A. Zhukov, T. Yao, Correlation between grain size and optical properties in zinc oxide thin films, Appl. Phys. Lett. 81 (2002) 1231-1233 https://doi.org/10.1063/1.1499991.

[43] O. Tuna, Y. Selamet, G. Ayhun, L. Ozyuzer, High quality ITO thin films grown by dc and RF sputtering without oxygen, J. Phys. D Appl. Phys. 43 (1-7) (2010), 055402 https://doi.org/10.1088/0022-3727/43/5/055402.

[44] F. Hai-Bo, Y. Shao-Yan, Z. Pan-Feng, W. Hong-Yuan, L. Xiang-Lin, J. Chun-Mei, Z. Qin-Sheng, C. Yong-Hai, W. Zhan-Guo, Investigation of oxygen vacancy and interstitial oxygen defects in $\mathrm{ZnO}$ films by photoluminescence and X-ray photoelectron spectroscopy, Chin. Phys. Lett. 43 (2010) 2108-2111 https: //doi.org/10.1088/0256-307x/24/7/089. 